\title{
High av Integrin Level of Cancer Cells Is Associated with Development of Brain Metastasis in Athymic Rats
}

\author{
YINGJEN JEFFREY WU ${ }^{1}$, MICHAEL A. PAGEL ${ }^{2}$, LESLIE L. MULDOON ${ }^{1,3}$, \\ RONGWEI FU ${ }^{4,5}$ and EDWARD A. NEUWELT ${ }^{1,2,6}$ \\ Departments of ${ }^{1}$ Neurology, ${ }^{3}$ Cell, Developmental \& Cancer Biology, ${ }^{5}$ Emergency Medicine and ${ }^{6}$ Neurosurgery, \\ Oregon Health \& Sciences University, Portland, OR, U.S.A.; \\ ${ }^{2}$ Veterans Administration Medical Center, Portland, OR, U.S.A.; \\ ${ }^{4}$ School of Public Health, Oregon Health \& Sciences University, Portland, OR, U.S.A.
}

\begin{abstract}
Background/Aim: Brain metastases commonly occur in patients with malignant skin, lung and breast cancers resulting in high morbidity and poor prognosis. Integrins containing an $\alpha v$ subunit are cell adhesion proteins that contribute to cancer cell migration and cancer progression. We hypothesized that high expression of $\alpha v$ integrin cell adhesion protein promoted metastatic phenotypes in cancer cells. Materials and Methods: Cancer cells from different origins were used and studied regarding their metastatic ability and intetumumab, anti- $\alpha v$ integrin $m A b$, sensitivity using in vitro cell migration assay and in vivo brain metastases animal models. Results: The number of brain metastases and the rate of occurrence were positively correlated with cancer cell $\alpha v$ integrin levels. High $\alpha v$ integrin-expressing cancer cells showed significantly faster cell migration rate in vitro than low av integrin-expressing cells. Intetumumab significantly inhibited cancer cell migration in vitro regardless of av integrin expression level. Overexpression of $\alpha v$ integrin in cancer cells with low $\alpha v$ integrin level accelerated cell migration in vitro and increased the occurrence of brain metastases in vivo. Conclusion: $\alpha v$ integrin promotes brain metastases in cancer cells and may mediate early steps in the metastatic cascade, such as adhesion to brain vasculature. Targeting $\alpha v$ integrin with intetumumab could provide clinical benefit in treating cancer patients who develop metastases.
\end{abstract}

This article is freely accessible online.

Correspondence to: Edward A. Neuwelt, MD, Oregon Health \& Sciences University, L603, 3181 SW Sam Jackson Park Road, Portland OR 97239, U.S.A. Tel: +1 5034945626, Fax: +1 5034945627,e-mail: neuwelte@ohsu.edu

Key Words: Integrin, intetumumab, brain metastasis, breast cancer, lung cancer, melanoma.
Brain metastases from systemic cancers occur in approximately $20 \%$ of lung cancer, $8 \%$ of melanoma, and $5 \%$ of breast cancer patients $(1,2)$. Patients with symptomatic central nervous system lesions that do not receive local treatment have a median overall survival of 2-4 months. Though prophylactic cranial irradiation is an approved prevention strategy in patients with small cell lung cancer, radiation is not appropriate for cancer types carrying a lower risk of metastatic brain disease due to long-term cognitive impairments $(3,4)$. Therefore, more effective approaches to prevent and treat brain metastases are needed to improve the quality of life and survival of cancer patients.

Integrins are a family of cell adhesion proteins that mediate adhesion between cells and between cells and their extracellular environment (5). These molecules consist of dimers of $18 \alpha$ and $8 \beta$ subunits and are known to promote the survival, proliferation and motility of tumor cells and tumor vascular endothelial cells (6-9). Intetumumab, anti- $\alpha \mathrm{v}$ integrin monoclonal antibody, has demonstrated antimigratory and anti-proliferative effects in vitro (10-12) as well as therapeutic and preventive effects in preclinical models $(11,13,14)$. However, these promising benefits have not yet been transferred to the clinical setting (15-17).

Using a hematogenous breast cancer brain metastasis model, we previously found that treating rats with intetumumab intravenously before or after cell infusion, or mixing cells with intetumumab prior to intracarotid infusion, significantly decreased the number of brain metastases (14). The objective of the current study was to investigate the potential role of $\alpha \mathrm{v}$ integrin in the development of brain metastases among primary cancer cell lines of different origins.

\section{Materials and Methods}

Cell culture and reagents. Human cancer cell lines used in this study were human melanoma (A375 and A2058), small cell lung carcinoma (SCLC; LX-1, H146 and DMS79), non-small cell lung carcinoma (NSCLC; H2126, A549, H460 and H520) and breast 
cancer cells (MDA-MB-231BR-HER2). Human brain-seeking metastatic breast cancer cells (MDA-MB-231BR-HER2 were kindly provided by Dr. Pat Steeg (NCI, Bethesda, MD, USA) and LX-1 was originally obtained from Mason Research Institute (Worcester, MA, USA). The other cell lines were obtained from the American Type Culture Collection (Manassas, VA, USA). All cells were cultured with proper medium supplemented with serum and antibiotics. Cells were confirmed mycoplasma-free, used at low passage, harvested immediately prior to implantation and used only if viability exceeded $90 \%$. Intetumumab (fully human anti- $\alpha v$ integrin monoclonal antibody) was provided by Ortho Biotech Oncology R\&D (Radnor, PA, USA). Antibodies for immunohistochemistry were anti-human $\alpha v, \alpha 1, \beta 5$ integrin (Cell Signaling Technology, Danvers, MA, USA), anti-EphA2 (Proteintech, Rosemont, IL, USA), anti-human mitochondrial antigen (Chemicon/Millipore Temecula, CA, USA), and anti-tubulin (Sigma, St. Louis, MO, USA). Cyclophosphamide (Cytoxan ${ }^{\circledR}$ Bristol-Myers Squibb, Princeton, NJ, USA) was dissolved in sterile saline before use.

In vitro cell labeling with quantum dot for cell trafficking. To monitor or traffic the location of human cancer cells after intracarotid infusion, $10^{6}$ metastatic MDA-MB-231BR-HER2 breast cancer cells were labeled in vitro using a quantum dot (Qdot) Qtracker Cell Labeling kit (ThermoFisher Scientific, Waltham, MA, USA) following the manufacturer's protocol. Rats were perfused with saline and euthanized at 3 and 7 days after cancer cell infusion ( $n=3$ per time point). Brain vasculature-associated Qdot-labeled cancer cells were analyzed from three random fields of view using a fluorescent microscope after counterstained with Hoechst nuclei stain.

Cellular $\alpha v$ integrin overexpression (knock-in). For $\alpha \mathrm{v}$ integrin overexpression, pTag-integrin expression vector (Axxora LLC; San Diego, CA, USA) and empty vector (pTag without $\alpha \mathrm{v}$ integrin) control were used in knock-in experiments. Stably-transfected human cancer cells, overexpressing $\alpha \mathrm{v}$ integrin, were selected by neomycin (G418) resistance. Cellular integrin proteins expression was characterized using immunoblotting and immunofluorescence microscopy. In vitro cell migration was assessed using a $0.5-\mathrm{mm}$ gap closure wound healing and migration assay (Ibidi LLC, Verona, WI, USA). In vitro cell viability WST assay (ThermoFisher Scientific, Waltham, MA, USA) was used to measure cell proliferation. Western immunoblotting was performed as described previously (18).

Rat xenografted tumor models. The care and use of the animals was approved by the Institutional Animal Care and Use Committee (IACUC) and was under the supervision of the Department of Comparative Medicine at Oregon Health and Science University (OHSU). Female (200-250 g) athymic (rnu/rnu) and heterozygous (rnu/wt) rats from the OHSU breeding colony were housed in a room with a 12 -h light: dark cycle maintained at $22 \pm 2^{\circ} \mathrm{C}$. Food and water were supplied to all rats ad libitum. Rats were euthanized with $\mathrm{CO}_{2}$ inhalation at $20 \%$ weight loss or poor clinical condition as per IACUC regulations as a surrogate for survival.

Hematogenous metastases model. For the hematogenous metastases model, rats were pre-treated intraperitoneally with cyclophosphamide $(100 \mathrm{mg} / \mathrm{kg}) 24 \mathrm{~h}$ before and 2 weeks after tumor cell inoculation. We have shown that cyclophosphamide decreases innate immunity and increases VEGF production in rat tumor models (19), and is essential for optimal brain metastases in the rat model. Rats ( $n=4$ to 30 per each different cancer cell line) were anesthetized with isoflurane (5\% induction, 2\% maintenance Aerrane; Anaquest, Inc., Madison WI, USA). A catheter filled with heparinized saline was tied into the right external carotid artery and human cancer cells $\left(10^{6}\right.$ cells or number as indicated, suspended in $1 \mathrm{ml}$ saline) were infused retrograde into the right internal carotid artery (19).

For the in vivo melanoma metastases study, intetumumab $(30 \mathrm{mg} / \mathrm{kg})$ was given intravenously 3 times at $1 \mathrm{~h}$ prior to, 7 and 14 days after intracarotid fusion of $10^{6}$ A2058 cells. Rat brains ( $n=7$ per treatment group) were harvested for immunohistochemical analysis at 21 days after infusion.

Intracerebral tumor model. Rats were anesthetized with ketamine $(60 \mathrm{mg} / \mathrm{kg})$ and diazepam $(7.5 \mathrm{mg} / \mathrm{kg})$ intraperitoneally. Rats $(\mathrm{n}=8$ per each clone of $\mathrm{H} 520$ or A375 cell) received $10^{6}$ human cancer cells in a volume of $15 \mu \mathrm{l}$, stereotactically injected (20) in the right caudate putamen (vertical, bregma $6.5 \mathrm{~mm}$; lateral, bregma 3.1 $\mathrm{mm})$. Rats were euthanized and brains were harvested for immunohistochemical analysis at 56 days after inoculation or when neurological symptoms occurred.

Histology and immunohistochemistry. Brains were excised and fixed in $10 \%$ buffered formalin for vibratome sectioning, $100 \mu \mathrm{m}$ in the coronal plane. For intracerebral tumor volumetrics, every 5 th brain section was stained for human mitochondrial antigen and then imaged at high resolution ( $30 \mu \mathrm{m}$ pixel diameter) on an Epson 1640XL flatbed scanner using Adobe Photoshop software. The volume of individual metastases and total tumor burden was assessed using NIH ImageJ software. Immunohistochemistry was performed by incubating brain slides with primary antibodies (1:200-1:1,000 dilution) in blocking buffer overnight at $4^{\circ} \mathrm{C}$ followed by biotinylated secondary antibody and visualization with a Vectastain ABC kit (Vector Laboratories, Burlingame, CA, USA) using diaminobenzidine (19).

Data analysis and statistical analysis. Immunoblotting signal of proteins was quantified using UN-SCAN-IT Gel software (Silk Scientific, Inc., Orem, UT, USA). An un-paired Student's $t$-test was used to compare quantum-dot labeled cells in brains. For the in vitro wound healing assay, different cell lines and treatments were compared using a one-way ANOVA and Tukey's test. For the in vivo animal studies, the difference of tumor occurrence rate was measured using Fisher's exact test. The difference in tumor volumes between treatment groups was compared using a non-parametric Wilcoxon sum test. All analyses were performed with Graphpad Prism version 6.04 or Microsoft Excel. Statistical significance between treatment and control (or vehicle) group or any two other groups was indicated by $p<0.05$ or $p<0.01$.

\section{Results}

To better understand the brain metastases cascade occurring after intra-carotid infusion, we tracked the location of metastatic human cancer cells by Quantum dot labeled MDA-MB-231BR-HER2 breast cancer cells in vitro. All labeled breast cells were found associated with brain vasculature at 3 days (either adhered to blood vessel walls or still in the circulation). About $50 \%$ of the labeled breast 

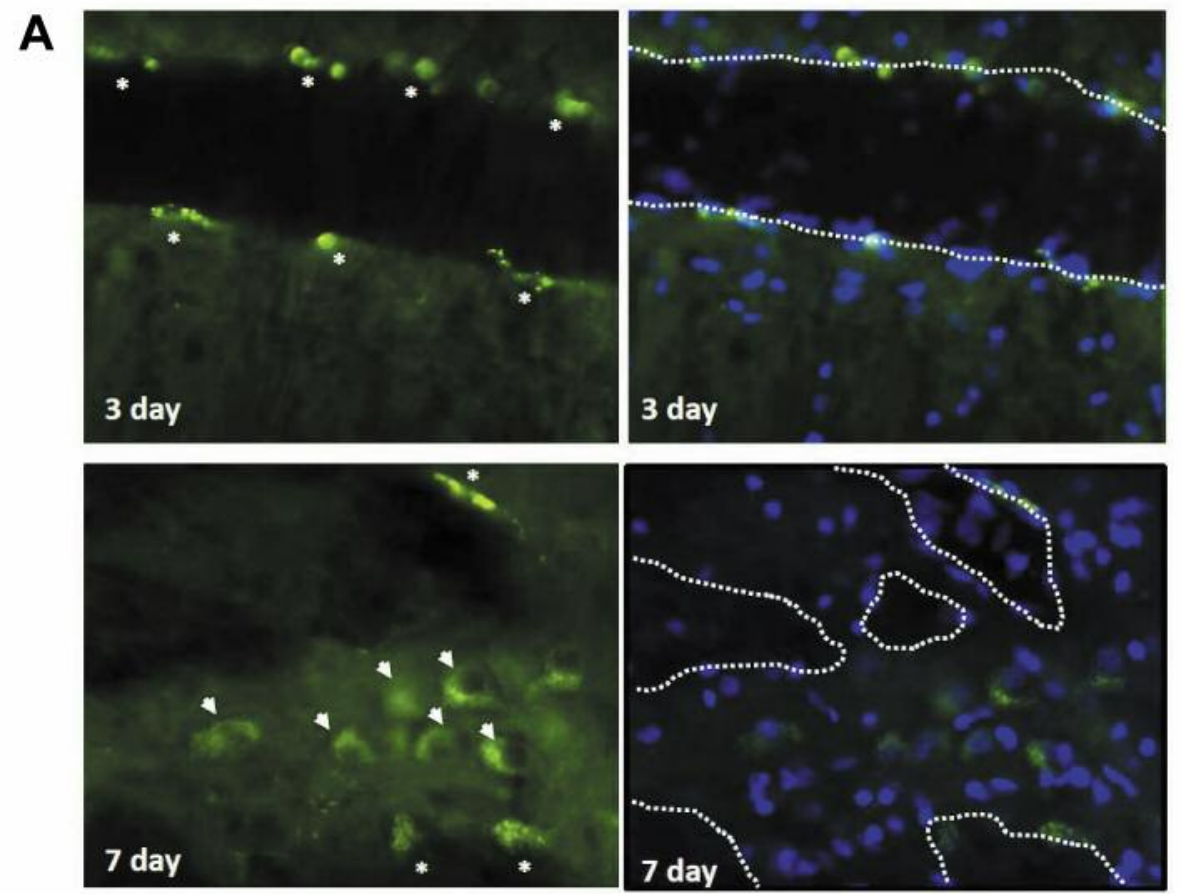

B

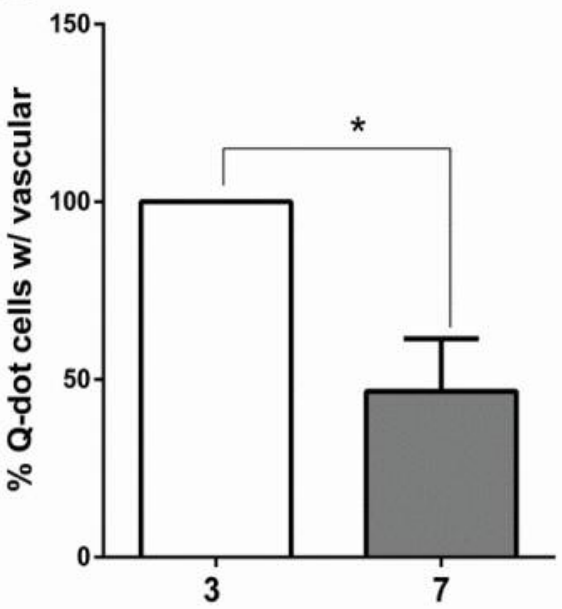

Day after IA infusion

cells transmigrated into brain parenchyma at 7 days after infusion (Figure 1A and B). We next assessed the role of $\alpha \mathrm{v}$ integrin cell adhesion protein in the metastatic phenotype of a broad range of human cancer cell lines expressing different level of $\alpha \mathrm{v}, \alpha 1$, and $\beta 5$ integrin and EphA2 from lung, melanoma and breast primary cancer origins (Figure 2A and B). The brain metastasis occurrence rate, approximate number of metastases, total tumor volume and survival time in rats with hematogenous brain metastases is summarized in Table I. With the pool of 10 cell lines tested, we found that the incidence and number of brain metastases formation
Figure 1. Cell trafficking of mestatatic breast cancer cells after intracarotid infusion. Athymic rats were intra-carotid infused metastatic MDA-MB-231BR-HER2 breast cancer cells $\left(10^{6}\right)$ after in vitro labeling with quantum dot ( $Q$-dot) using Qtracker Cell Labeling kit. Brains $(n=3$ per time point) were harvested from rats at 3 and 7 days after $10^{6}$ cell infusion. A) Brain vasculature and parenchyma associated Q-dot labeled cancer cells indicated by asterisks and arrowheads, respectively. Brain tissues were counterstained with Hoechst nuclei stain. Putative brain vasculatures were outlined by dashed white line. B) Percentage of vasculature associated $Q$-dot labeled cells were analyzed from three random fields of view under fluorescent microscopy and represented as mean \pm SEM. ${ }^{*} p<0.05$ between 2 groups.

was positively correlated $\left(\mathrm{R}^{2}=0.81\right)$ to cellular $\alpha \mathrm{v}$ integrin level normalized by tubulin expression after intra-carotid infusion (Figure 2C). There was no significant correlation of brain metastasis incidence found with other adhesion proteins investigated.

Cells that expressed high $\alpha v$ integrin levels (A549 NSCLC and A2058 melanoma) showed a higher cell migration rate than cells expressing low $\alpha \mathrm{v}$ integrin levels (H520 NSCLC and A375 melanoma), as assessed by rate of a $0.5-\mathrm{mm}$ gap closure in an in vitro wound healing migration assay (Figure 3). In 4 different cancer cell lines, the time needed for gap closure was 
Table I. Summary of brain metastasis development among different cancer cell lines in athymic rats.

\begin{tabular}{|c|c|c|c|c|c|c|}
\hline Cancer type & Cell line & $\alpha_{V}$ integrin $^{1}$ & Metastasis incidence $^{2}$ & Tumor no. ${ }^{3}$ & Tumor vol. ${ }^{4}$ & Survival $^{5}(\mathrm{~d})$ \\
\hline \multicolumn{7}{|c|}{ Lung carcinoma } \\
\hline \multirow{3}{*}{ Small cell } & LX1 & Medium & $3 / 30(10 \%)$ & $1 \pm 0$ & $0.1-78$ & 36 \\
\hline & H146 & Low-medium & $0 / 4(0 \%)$ & 0 & 0 & - \\
\hline & DMS79 & Low & $0 / 4(0 \%)$ & 0 & 0 & - \\
\hline \multirow[t]{4}{*}{ Non-small } & $\mathrm{H} 460$ & High & $4 / 4(100 \%)$ & $13 \pm 6$ & $0.05-55$ & 34 \\
\hline & $\mathrm{H} 2126$ & Medium-high & $0 / 4(0 \%)$ & 0 & 0 & - \\
\hline & A549 & High & $6 / 6(100 \%)$ & $9 \pm 5$ & $0.05-126$ & 62 \\
\hline & $\mathrm{H} 520$ & Low & $0 / 4(0 \%)$ & 0 & 0 & - \\
\hline \multirow[t]{3}{*}{ Melanoma } & A 375 & Low & $3 / 4(75 \%)$ & $1 \pm 0$ & $3.2-63$ & 67 \\
\hline & A2058 & High & $4 / 4(100 \%)$ & $140 \pm 70$ & $0.05-7.8$ & 29 \\
\hline & A2058 6 & High & $14 / 14(100 \%)$ & $96 \pm 66$ & $0.02-24$ & - \\
\hline Breast cancer & MDA-MB-231BR-HER2 & High & 9/9 (100\%) & $15 \pm 9$ & $91-316$ & 52 \\
\hline
\end{tabular}

Brain metastases were produced by intra-carotid infusion of $10^{6}$ human cancer cells in nude rats pre-treated intraperitoneally with cyclophosphamide $(100 \mathrm{mg} / \mathrm{kg}) 1$ day before and 14 days after cell inoculation. ${ }^{1}$ Cancer cell $\alpha \mathrm{v}$ integrin level was measured by immunoblotting after normalization with $\beta$-tubulin. ${ }^{2}$ Brain metastasis incidence was calculated by no. of rats with brain metastasis/no. of rat injected. ${ }^{3}$ Number of tumors per brain in rats with brain metastases is indicated as mean $\pm \mathrm{SD}$. ${ }^{4}$ Tumor volume indicates range in $\mathrm{mm}^{3} .{ }^{5}$ Survival (mean day after cell infusion) is shown for animals that were euthanized at $20 \%$ body weight loss for tumor burden; all non-tumor bearing rats were euthanized at 84 days after cell infusion or 3 weeks post infusion in A2058 melanoma. ${ }^{6} 10^{5}$ A2058 melanoma cells were given by intra-carotid infusion.

negatively correlated $\left(\mathrm{R}^{2}=0.75\right)$ to their $\alpha \mathrm{v}$ integrin level (Figure 3D). Additionally, this time was also negatively correlated $\left(\mathrm{R}^{2}=0.72\right)$ to the number of brain metastases formed (Figure 3E) and mimicked the metastatic phenotype and characteristics of these cells in vivo (Figure 2B and Table I). In particular, A2058 melanoma cells had the highest migration rate, closing the $0.5-\mathrm{mm}$ gap within $12 \mathrm{~h}$ (Figure 3C), and these cells also induced brain metastases in $100 \%$ of rats after intracarotid inoculation, with the highest number of metastases $(140 \pm 70$ metastases per brain) and the shortest median survival (29 days; $n=26$ ). In contrast, low $\alpha v$ integrin-expressing A375 melanoma cells took 6 days to close the $0.5-\mathrm{mm}$ gap (Figure 3B), and only formed one brain metastasis per brain in 3 of 4 test animals with a median survival of 67 days. In the NSCLC models, A549 (high av) and H520 (low $\alpha \mathrm{v}$ ) cells closed the 0.5 -mm gap after 3 days and 7 days in vitro, and developed $9 \pm 5$ and zero brain metastases, respectively, after intra-carotid infusion of $10^{6}$ cells.

Intetumumab treatment $(50 \mu \mathrm{g} / \mathrm{ml})$ significantly inhibited in vitro cell migration of 3 out of 4 tested cell lines (A549, $\mathrm{H} 520$ and A375) by delaying the time to gap closure in both the high and low $\alpha \mathrm{v}$ integrin cells (Figure 3A-C). However, high $\alpha v$ integrin-expressing A2058 melanoma cells were found to be resistant to intetumumab with an effective inhibitory concentration of 10 times or higher $(>0.5 \mathrm{mg} / \mathrm{ml}$; Figure 3C). Similarly, rats treated $30 \mathrm{mg} / \mathrm{mL}$ intetumumab intravenously ( $n=7$ per treatment group) failed to reduce the number of A2058 melanoma induced brain metastases (Figure 3F) and tumor volume (Figure 3G) when compared to control.
To validate the role of $\alpha v$ integrin in cell invasion and migration, we over-expressed $\alpha \mathrm{v}$ integrin in A375 melanoma and H520 NSCLC cells (parental cells with low av) using a TagRFP-integrin vector. In the A375 melanoma cells, $\alpha \mathrm{v}$ integrin was overexpressed about 2.5 -fold by pTagRFP-integrin vector without affecting tubulin level (Figure 4A). Compared to the empty vector control, A375 $\alpha \mathrm{v}$ integrin-overexpressing cells showed accelerated cell migration in vitro, with decreased time for gap closure (4 vs. 6 days; $p<0.05$; Figure 4B) without affecting cell proliferation rate (data not shown). After intracerebral inoculation, $\alpha \mathrm{v}$ integrin overexpressing A375 melanoma significantly $(p=0.007)$ increased the brain tumor occurrence rate (100\%; 8/8 vs. 25\%; 2/8) by Fisher's exact test, without affecting tumor volume $(76.7 \pm 75.6 \mathrm{vs}$. $114.7 \pm 104.4 \mathrm{~mm}^{3}$; Figure $4 \mathrm{C}$ and D). Similar results were obtained when H520 NSCLC were transfected with the same TagRFP-integrin vector (Figure 5). There was no statistical significance in brain tumor volume $(36.3 \pm 22.6 \mathrm{vs}$. $61.4 \pm 53.5 \mathrm{~mm}^{3}$ ) after intracerebral inoculation, even with 5 -fold $\alpha \mathrm{v}$ integrin upregulation (clone \#2). Intracerebral inoculation with $\alpha \mathrm{v}$ integrin knockin H520 NSCLC cells doubled the brain tumor occurrence rate $(75 \% ; 6 / 8$ vs. $37.5 \%$; $3 / 8)$ compared to the empty vector control, though this result was not statistically significant $(p=0.315)$, possibly due to our small sample size. Overall, our results suggest that $\alpha \mathrm{v}$ integrin plays more important roles in cancer cell adhesion to brain vasculature than cell proliferation for the development of brain tumor in both hematogenous and intracerebral brain metastases models. 
A
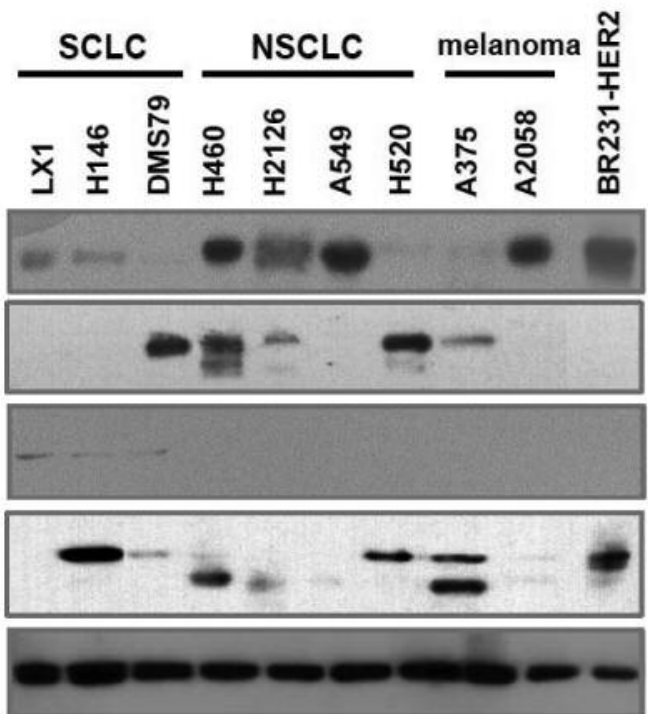

C

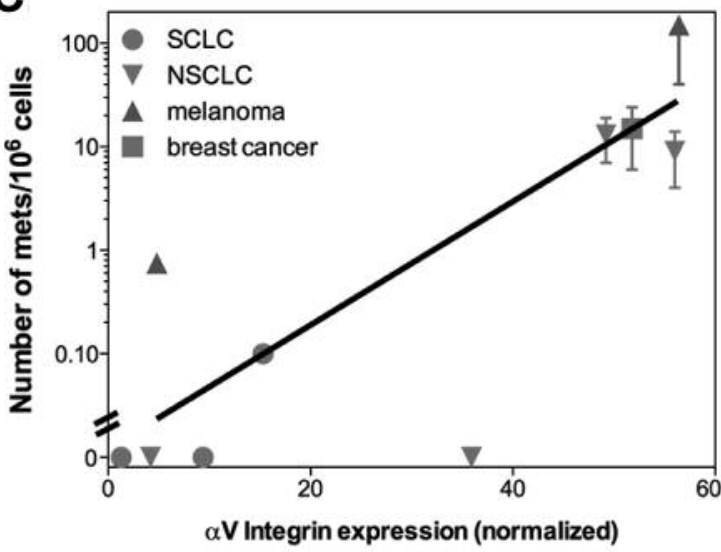

B

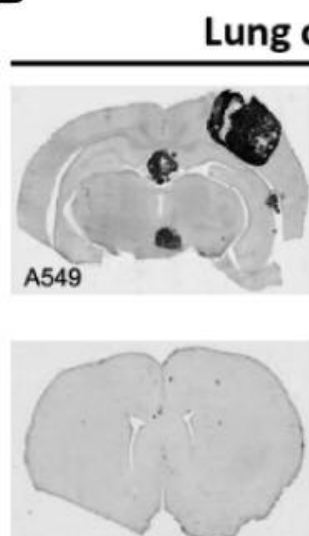

H520, H2126, H146, DMS79
EphA2

tubulin

av integrin

$\beta 5$ integrin

a1 integrin

Figure 2. Human cancer cell $\alpha v$ integrin protein level correlates with brain metastasis formation in vivo. A) Immunoblot showing variable $\alpha v$, $\alpha 1$, $\beta 5$ integrin and EphA2 protein levels in different metastatic human tumor cells from multiple origins. B) Brain immunohistochemistry of one representative rat from each of the indicated hematogenous metastasis models. Sections were stained for human mitochondrial antigen (hematoxylin in LX1 SCLC) as a marker of human tumor growth. C) Correlation of $\alpha v$ integrin and number of brain metastases $\left(R^{2}=0.81\right)$. The immunoblotting band intensity was normalized to tubulin as a loading control.

\section{Discussion}

Brain metastases is an inefficient process with less than $0.1 \%$ of cancer cells eventually developing brain tumors after intra-carotid infusion in the hematogenous metastasis model. It requires that cancer cells leave their primary site, travel and survive inside blood circulation, recognize, bind to, and migrate through brain vasculature, infiltrate into brain parenchyma, and thrive in the brain microenvironment (21-
24). The mechanisms involved in this cascade remain unclear. Experimental brain metastases models using intracardiac, intra-carotid, or orthotopic inoculation of cancer cells have been established previously $(14,19,25)$. In this study of 10 human cancer cell lines that have been confirmed to form tumors after intracerebral implantation, several cell lines formed no brain metastases after intra-carotid infusion. Overall, we found an average of only 10 brain metastases (ranging from 0 to 150 ) after infusing $10^{6}$ cells. We 


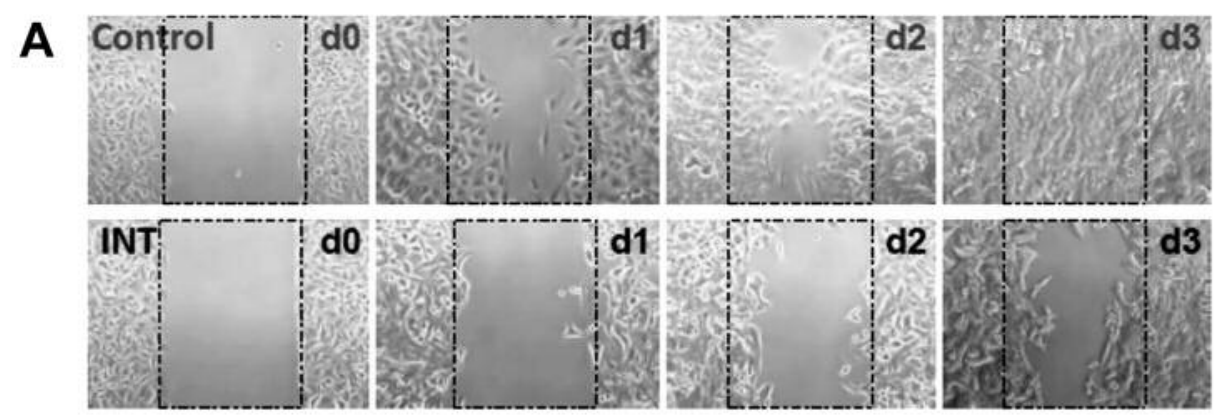

\section{B}

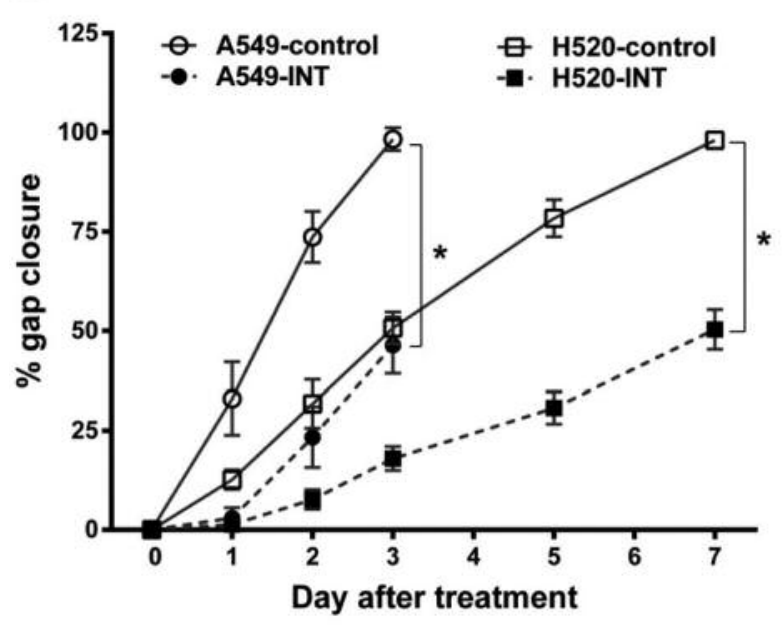

D

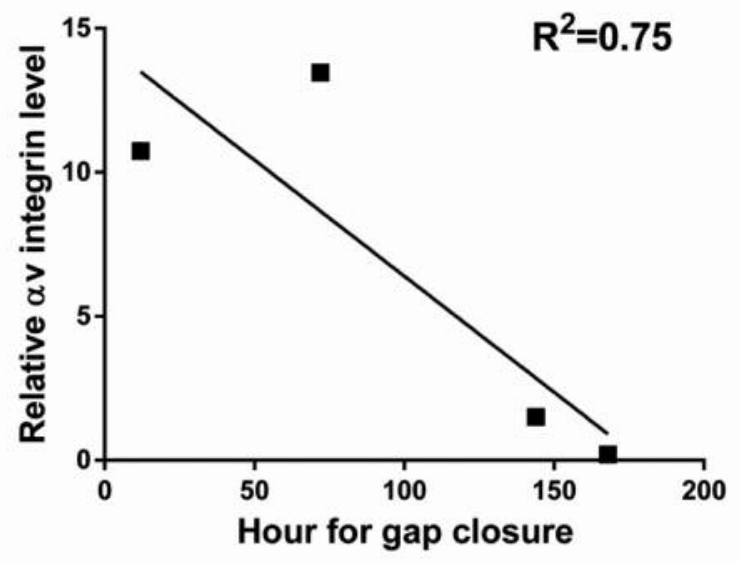

C

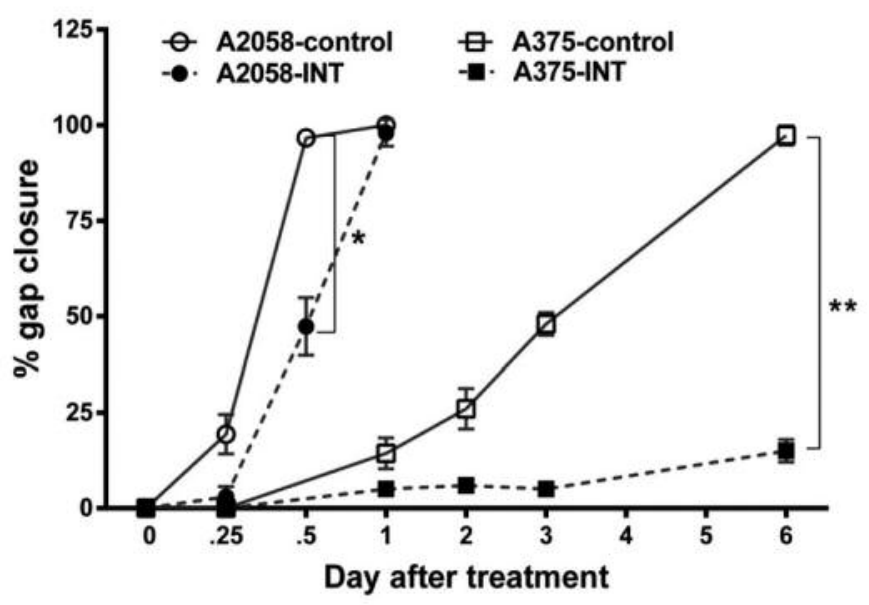

E

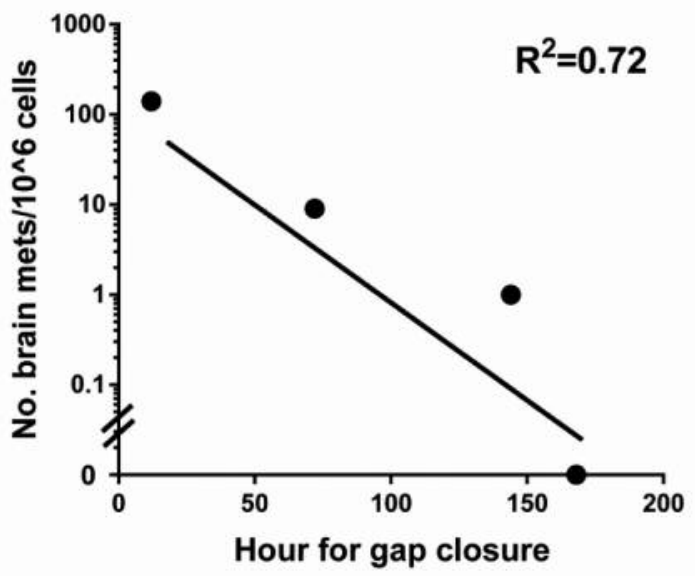

Figure 3. Continued

demonstrated that the incidence and number of brain metastases formation was positively correlated $\left(\mathrm{R}^{2}=0.81\right)$ to cellular $\alpha v$ integrin level after intra-carotid inoculation even with a small $(n=10)$ pool of cell lines tested. Our data suggest that $\alpha \mathrm{v}$ integrin plays important roles in cancer cell recognition and adhesion to brain vasculature and parenchyma infiltration for the development of brain tumors. Our results support the previous findings that integrins are overexpressed in malignant cells, and promote invasion and metastasis $(7,9)$. Vogetseder et al. (26) found elevated levels of $\alpha v \beta 3, \alpha v \beta 6$, and $\alpha v \beta 8$ integrin in human breast cancer brain metastases. The $\alpha v$ integrins are expressed on the 
$\mathbf{F}$

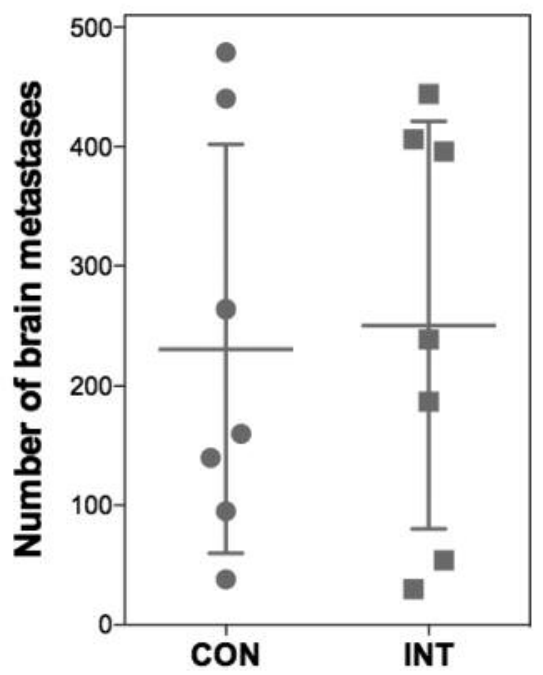

G

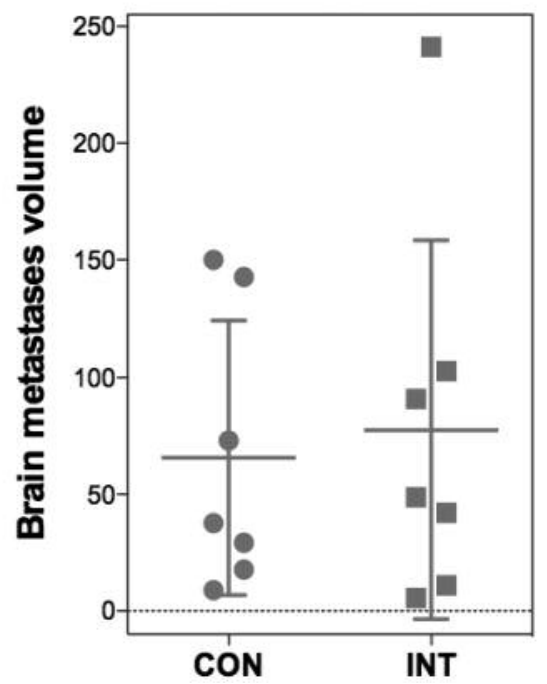

Figure 3. Role of $\alpha v$ integrin in cell migration in vitro and effect of intetumumab in cell migration and melanoma brain metastases in vivo. A) Representative micrographs of A549 non-small cell lung carcinoma (NSCLC) cells that were untreated (control) or treated with intetumumab $\left(50 \mu \mathrm{g} / \mathrm{ml}\right.$; bottom) in the in vitro cell migration assay (ibidi ${ }^{\circledR} \mu$-dish culture insert, Verona, WI, USA); B) Quantification of NSCLC in vitro cell migration assay. A549 (high $\alpha$ v) cells are more invasive than A375 cells with shorter time ( 3 vs. 7 days) to close the 0.5 mm gap; C) Quantification of melanoma in vitro cell migration assay. A2058 (high av) melanoma is more invasive than A375 cells. Intetumumab dose used to treat A2058 and A375 melanoma is 750 and $50 \mu \mathrm{g} / \mathrm{ml}$, repectively. Error bars show $S D$ and $*$ and $* *$ indicates values $p<0.05$ and $p<0.01$ in comparison to control group, respectively; D) Correlation of hour needed for gap closure and cellular $\alpha v$ integrin level $\left(R^{2}=0.75\right)$ among 4 cancer cell lines studied; E) Correlation of hour needed for gap closure and number of brain metastases in vivo $\left.\left(R^{2}=0.72\right) ; F, G\right)$ Compared to control (CON), 3 times treatment of intetumumab (INT, $30 \mathrm{mg} / \mathrm{ml}$, IV) failed to reduce number of A2058 melanoma brain metastases $F$ ) and tumor volume G).

surface of most epithelial tumors and expression is altered in tumor progression and metastasis $(27,28)$. In contrast, Hoshino et al. (29) found that tumor exosomes rich in integrin $\alpha 2$ are more brain-tropic and $\alpha \mathrm{v}$ integrin is more involved in liver metastases. Recently, Chen et al. (30) demonstrated that connexin 43 and protocadherin 7 are overexpressed in brain- compared to bone- or lung-trophic clones of MDA-MB-231 human breast cancer cell. Brain-trophic H2030 NSCLC also has elevated levels of these two proteins compared to its parental counterpart.

Cancer cells with low $\alpha \mathrm{v}$ integrin will loosely bind to extracellular matrix (ECM) of brain parenchyma after intracarotid or intracerebral inoculation and few of them will further develop brain lesions (31). Stapack et al. (32) found that the absence of $\alpha v \beta 1$ and $\alpha v \beta 3$ mediated attachment to the ECM can trigger anoikis (apoptosis due the absence of cell-matrix interaction) and apoptosis. Integrin signaling through growth factors and cytokines induces tumor cell growth and motility and blocks apoptosis (33, 34). Morozevich et al. (35) showed that $\alpha \mathrm{v} \beta 3$ integrin expression of human intestinal carcinoma cells became resistant to anoikis. Moreover, expression of $\alpha v \beta 3$ integrin in glioma cells increases survival in response to stress (36) and cilengitide, an $\alpha v \beta 3$ and $\alpha v \beta 5$ antagonist, treatment blocked the fibroblast senescence without affecting proliferation (37) and inhibits pulmonary metastasis in an intramuscular osteosarcoma xenograft mouse model (38). Xiong et al. (39) found that transforming growth factor- $\beta 1$ induces endometrial cancer cell adhesion and migration by upregulating $\alpha v \beta 3$ integrin. Knockdown of integrin $\alpha v$ induced loss of the metastatic phenotype in human prostate and breast cancer cells (40-43). In support of this, we found that cell migration, as measured by the gap closure time in vitro, was negatively correlated to their $\alpha v$ integrin level and number of brain metastases in vivo (Figure 3D and E). Overall, our findings suggested that cellular $\alpha \mathrm{v}$ integrin level and in vitro migration assay data could potentially be used to predict the in vivo brain metastasis outcome.

Chen et al. showed that intetumumab prevents integrin binding to ECM molecules (11), which prevents downstream molecular interactions for cancer cell migration, invasion, and successful metastasis $(6,34)$. In the current study, we found that intetumumab $(50 \mu \mathrm{g} / \mathrm{ml})$ reduced cell migration of A549, H520 and A375 but not A2058 cells regardless of $\alpha \mathrm{v}$ integrin level. Compared to A549 NSCLC, highly invasive A2058 with similar $\alpha$ v integrin level is extremely 
A
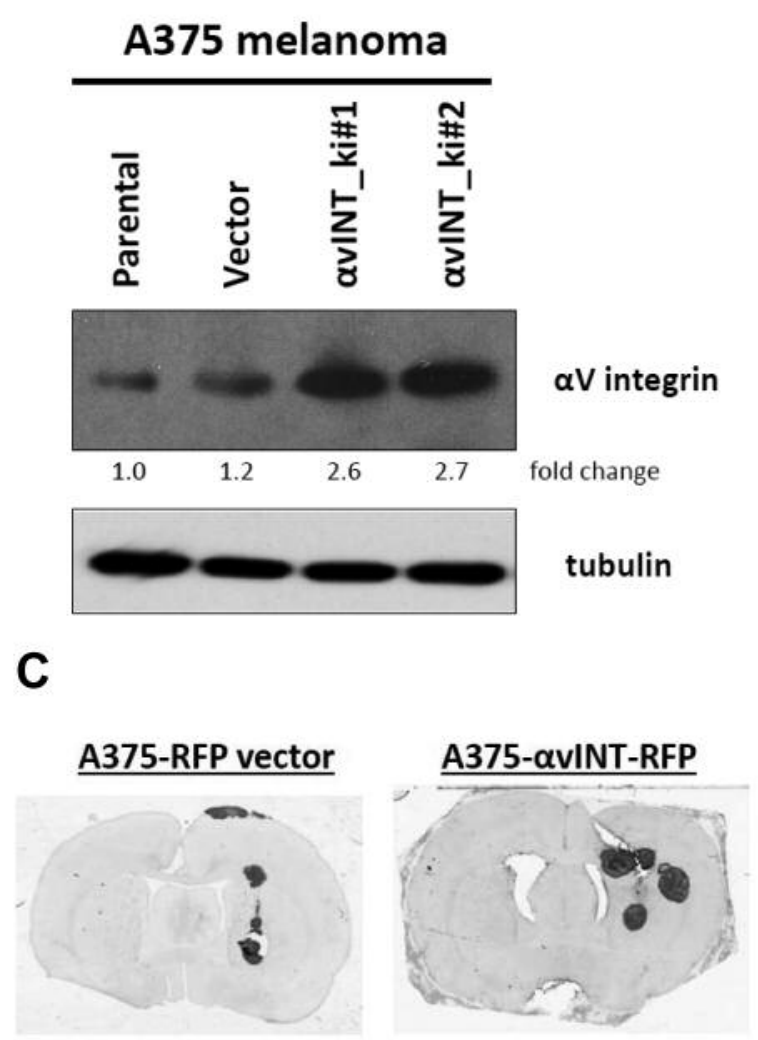

B

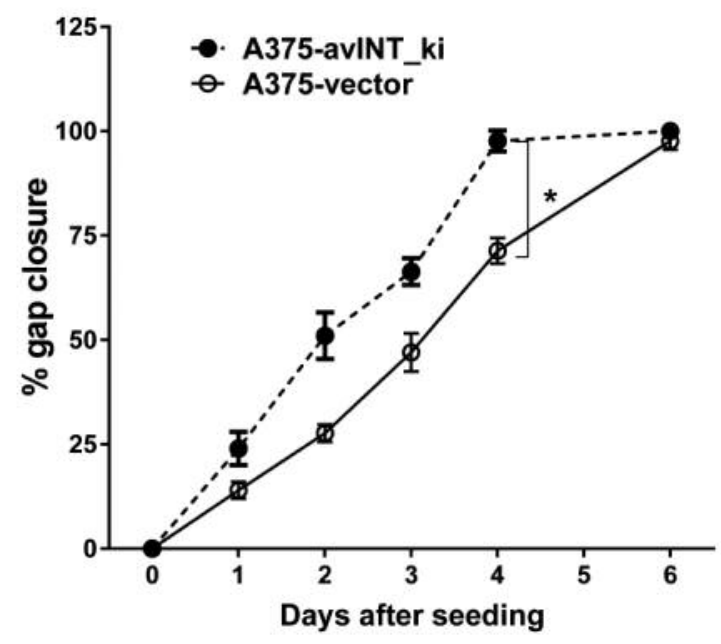

D

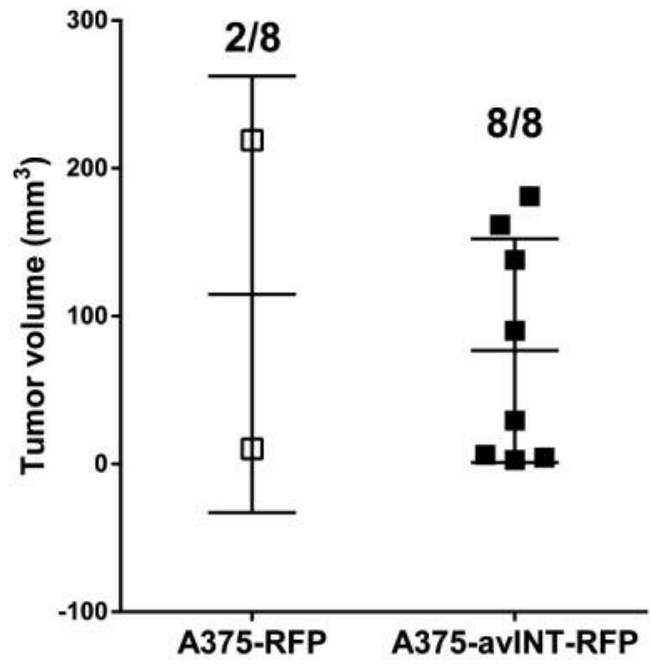

Figure 4. Overexpression of $\alpha v$ integrin increases A375 melanoma cell migration in vitro and tumor occurrence in vivo. A) $\alpha v$ integrin protein level in A375 cells including parental, vector only or $\alpha v$ integrin knock-in (avINT_ki) clones with tubulin as loading control; B) Quantification of in vitro cell migration assay among A375 clones. A375-avINT_ki cells are more invasive than A375 parental and vector cells with shorter time (4 vs. 6 days) to close the $0.5 \mathrm{~mm}$ gap. Error bars show $S D$ and $* p<0.05$ in comparison to control group; C) Brain immunohistochemistry of representative rats after intracerebral inoculation with $10^{6}$ A375 avINT-RFP\#2 and-RFP alone. Brains were stainned with human mitochondrial antigen after harvesting at 56 days after inoculation or when neurological symptom occurred; D) Dot plot chart of individual brain tumor volume and number of rats with tumor after inoculation shown in Figure 3C.

resistant to intetumumab both in vitro $(>500 \mu \mathrm{g} / \mathrm{ml})$ and in vivo $(30 \mathrm{mg} / \mathrm{kg}, \mathrm{IV})$ treatment. Previously, we found single or weekly administrations of intetumumab at lower dosage $(10 \mathrm{mg} / \mathrm{kg}, \mathrm{IV})$ reduced the incidence and number of breast cancer brain metastases in athymic rats (14). Liu et al. (44) found that STK11, KRAS mutation, ZEB1 upregulation and E-cadherin down-regulation was associated with intetumumab resistance in 23 lung cancer cell lines.
However, the molecular mechanism(s) involved in regulating integrin levels and intetumumab resistance are not defined and need further investigation.

We believe that $\alpha \mathrm{v}$ integrin of brain metastatic cells predominantly regulate cell adhesion, invasion and metastasis rather than cell proliferation and tumor growth. To evaluate the role of $\alpha \mathrm{v}$ integrin in invasion and proliferation, we demonstrated that overexpression of $\alpha \mathrm{v}$ integrin in A375 
A

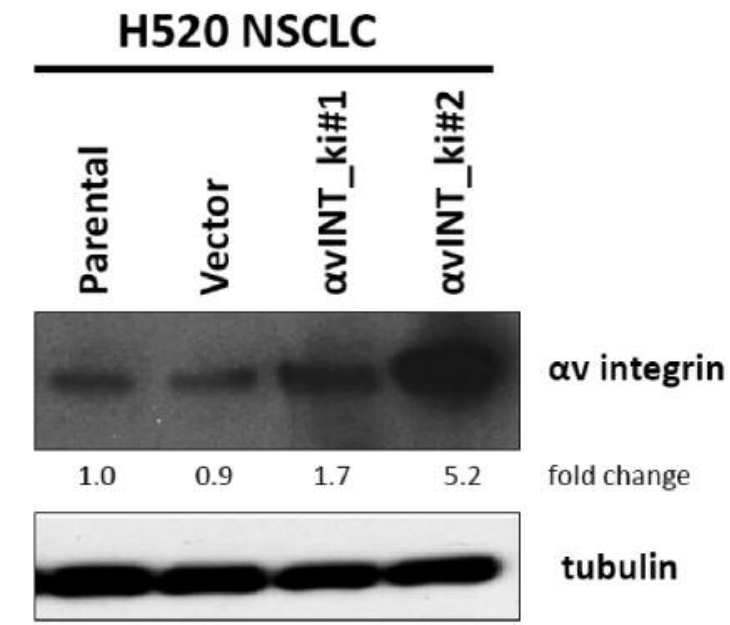

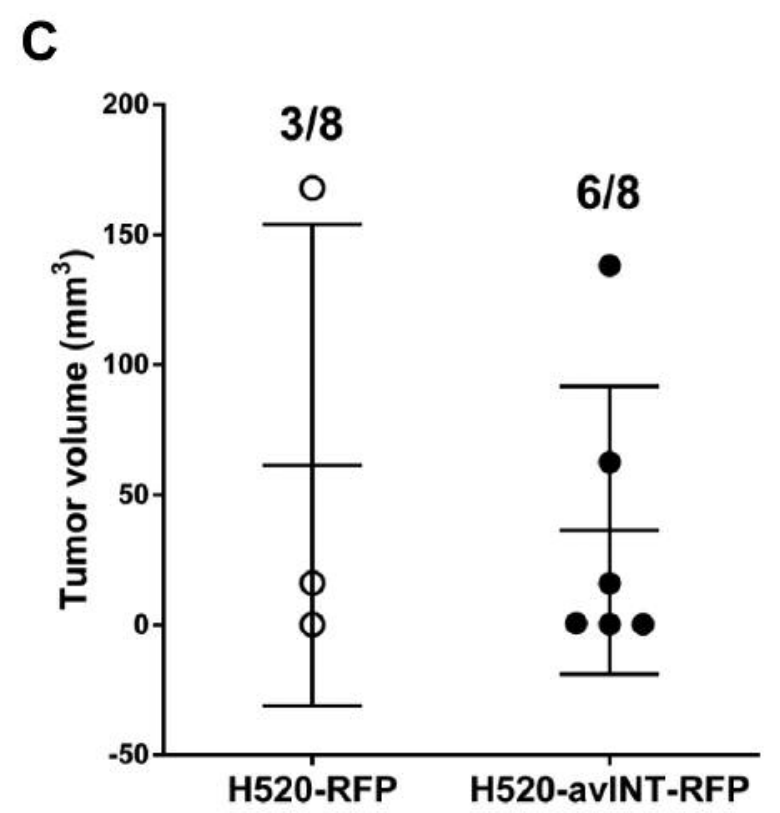

B

\section{H520-RFP vector}

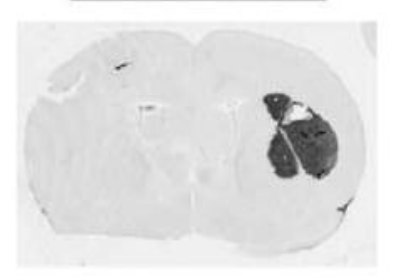

H520- $\alpha$ VINT-RFP

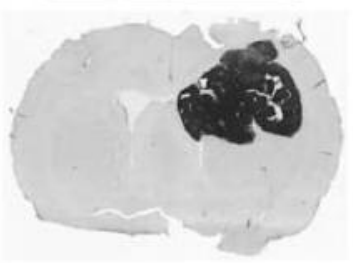

Figure 5. Overexpression of $\alpha v$ integrin in H520 NSCLC in vitro increases tumor occurrence after intracerebral inoculation. A) $\alpha v$ integrin protein level in H520 cells including parental, vector only or av integrin knock-in (avINT_ki) clones with tubulin as loading control. B) Brain immunohistochemistry of reprensentative rats stainned with human mitochondrial antigen; Athymic rats were intracerebrally inoculated with $10^{6}$ H520 avINT-RFP\#2 and-RFP alone, brains were harvested at 56 days after inoculation. C) Dot plot chart of individual brain tumor volume and number of rats with tumor after inoculation shown shown in Figure $4 B$.

increase cell invasion and motility in vitro without affecting proliferation rate (Figure 4). In the orthotopic metastasis model, we only found the difference of tumor occurrence rate (A375 and H520) but not the mean brain tumor volume after directly intracerebral inoculation. Thus, the observed increase in cell adhesion and tumorigenic occurrence did not result from higher cell numbers, but rather was a direct reflection of $\alpha \mathrm{v}$ integrin overexpression. Similarly, we found that $\alpha \mathrm{v}$ integrin-knockdown MDA-MB-231BR clones lose their invasiveness without affecting cell proliferation in vitro and in vivo (42). Our results are in agreement with Weber et al. who identified the activated $\alpha v \beta 3$ integrin in cancer cells and its interaction with platelets to promote extravasation as critical for early steps during hematogenous metastasis (45). McCarroll et al. (46) also showed that $\beta$ III-tubulin regulates lung cancer metastasis without altering growth of tumor cells in vivo in an anchorage-dependent manner. Parental (MDAMB-231) and brain metastatic cells (MDA-MB-231BR) do not exhibit differences in proliferation, although MDA-MB231BR showed a 2.5 -fold increase in $\beta$ III-tubulin protein levels (47). Jiang et al. (48) also demonstrated that targeting $\alpha \mathrm{v}$ integrin with abitumumab inhibited prostate cancer cell adhesion, migration and invasion, but not proliferation in vitro. MicroRNA-124 inhibited hepatocarcinoma cell invasion and migration by suppressing $\alpha \mathrm{v}$ integrin (49). Inhibition of $\alpha v \beta 3$ integrin by RGD disintegrin also induces loss of cell directionality and reduction of migration speed in oral squamous carcinoma cells (50). Cellular integrin regulation, trafficking and recycling is extremely complicated processes highly dependent upon the activation and ligand bound state of integrin $(28,51-53)$. In metastasizing cancer cells, where different integrin dimers are activated by different ECM 
ligands as these cells encounter multiple distinct microenvironments including brain (54). Therefore, switching between active and inactive states, proper trafficking and cellular localization of integrin dimers are critical to regulate their tumorigenic properties after cancer cells arriving at premetastatic niches such as brain neural-vascular unit.

A major limitation of this study is the use of intracerebral xenografts in the $\alpha \mathrm{v}$ integrin-overexpressing cancer cells. Intracerebral implantation does not recapitulate the metastatic cascade and does not fully mimic the heterogeneity of human brain metastasis localization or progression. We tested the transfected clones in vivo in the hematogenous metastasis paradigm. Unexpectedly, no animals receiving the cancer cells with modified $\alpha v$ integrin survived after intra-carotid injection. This was apparently due to stroke caused by cell clumping and/or larger cell size in a portion of the transfected cells. Attempts to filter clumped cells or dilute the cell infusate were unsuccessful. A second limitation of this study is that the detailed molecular mechanism(s) of in vitro intetumumab resistance of A2058 melanoma compared to A549 NSCLC remain unclear and need to be delineated.

In conclusion, our study demonstrated the concept that i) $\alpha v$ integrin plays more important roles in regulating cancer cell adhesion to brain vasculature than cell proliferation for the development of brain tumor; ii) cancer $\alpha v$ integrin levels from biopsy of primary tumor and their in vitro migration ability could potentially be used to predict the in vivo metastasis outcome; and iii) targeting $\alpha \mathrm{v}$ integrin including intetumumab may be used as an adjuvant to prevent and improve the survival in brain metastasis patients regardless of $\alpha v$ integrin level.

\section{Conflicts of Interest}

The Authors have no conflicts of interest to disclose.

\section{Acknowledgements}

This work was supported by the National Institutes of Health National Cancer Institute grant CA137488 and CA199111; a Veterans Administration Merit Review grant; a Department of Defense grant W81XWH; and the Walter S. and Lucienne Driskill Foundation, all to Edward A. Neuwelt. These authors would also like to thank Ms. DreeAnna Morris for her technical support.

\section{References}

1 Lowery FJ and Yu D: Brain metastasis: Unique challenges and open opportunities. Biochim Biophys Acta 1867: 49-57, 2017.

2 Shonka N, Venur VA and Ahluwalia MS: Targeted Treatment of Brain Metastases. Curr Neurol Neurosci Rep 17: 37-48, 2017.

3 Beasley KD and Toms SA: The molecular pathobiology of metastasis to the brain: a review. Neurosurgery Clinics North America 22: 7-14, 2011
4 Eichler AF, Chung E, Kodack DP, Loeffler JS, Fukumura D and Jain RK: The biology of brain metastases-translation to new therapies. Nat Rev Clin Oncol 8: 344-356, 2011.

5 Manninen A and Varjosalo M: A proteomics view on integrinmediated adhesions. Proteomics 17(3-4), 2017. doi: 10.1002/pmic.201600022

6 Desgrosellier JS, Barnes LA, Shields DJ, Huang M, Lau SK, Prevost N, Tarin D, Shattil SJ and Cheresh DA: An integrin alpha(v)beta(3)-c-Src oncogenic unit promotes anchorageindependence and tumor progression. Nat Med 15: 1163-1169, 2009.

7 Felding-Habermann B: Integrin adhesion receptors in tumor metastasis. Clin Exp Metastasis 20: 203-213, 2003.

8 Hynes RO: Integrins: bidirectional, allosteric signaling machines. Cell 110: 673-687, 2002.

9 Seguin L, Desgrosellier JS, Weis SM and Cheresh DA: Integrins and cancer: regulators of cancer stemness, metastasis, and drug resistance. Trends Cell Biol 25: 234-240, 2015.

10 Thompson EM, Whitney NL, Wu YJ and Neuwelt EA: The effect of alpha- $v$ integrin inhibition on the malignant characteristics of medulloblastoma. J Neurosurg Pediatr 11: 6067, 2013.

11 Chen Q, Manning CD, Millar H, McCabe FL, Ferrante C, Sharp C, Shahied-Arruda L, Doshi P, Nakada MT and Anderson GM: CNTO 95, a fully human anti alphav integrin antibody, inhibits cell signaling, migration, invasion, and spontaneous metastasis of human breast cancer cells. Clin Exp Metastasis 25: 139-148, 2008.

12 Trikha M, Zhou Z, Nemeth JA, Chen Q, Sharp C, Emmell E, Giles-Komar J and Nakada MT: CNTO 95, a fully human monoclonal antibody that inhibits alphav integrins, has antitumor and antiangiogenic activity in vivo. Int J Cancer 110: 326-335, 2004.

13 Ning S, Tian J, Marshall DJ and Knox SJ: Anti-alphav integrin monoclonal antibody intetumumab enhances the efficacy of radiation therapy and reduces metastasis of human cancer xenografts in nude rats. Cancer Res 70: 7591-7599, 2010.

14 Wu YJ, Muldoon LL, Gahramanov S, Kraemer DF, Marshall DJ and Neuwelt EA: Targeting $\alpha \mathrm{v}$ integrins decreased metastasis and increased survival in a nude rat breast cancer brain metastasis model. J Neuro-Oncol 110: 27-36, 2012.

15 Heidenreich A, Rawal SK, Szkarlat K, Bogdanova N, Dirix L, Stenzl A, Welslau M, Wang G, Dawkins F, de Boer CJ and Schrijvers D: A randomized, double-blind, multicenter, phase 2 study of a human monoclonal antibody to human alpha $\mathrm{v}$ integrins (intetumumab) in combination with docetaxel and prednisone for the first-line treatment of patients with metastatic castrationresistant prostate cancer. Annals Oncol 24: 329-336, 2013.

16 O'Day S, Pavlick A, Loquai C, Lawson D, Gutzmer R, Richards J, Schadendorf D, Thompson JA, Gonzalez R, Trefzer U, Mohr P, Ottensmeier C, Chao D, Zhong B, de Boer CJ, Uhlar C, Marshall D, Gore ME, Lang Z, Hait W, Ho P and CNTO 95 Investigators.: A randomised, phase II study of intetumumab, an anti-v-integrin $\mathrm{mAb}$, alone and with dacarbazine in stage IV melanoma. Br J Cancer 105: 346-352, 2011.

$17 \mathrm{Kim}$ KB, Prieto V, Joseph RW, Diwan AH, Gallick GE, Papadopoulos NE, Bedikian AY, Camacho LH, Hwu P, Ng CS, Wei W, Johnson MM, Wittemer SM, Vardeleon A, Reckeweg A and Colevas AD: A randomized phase II study of cilengitide (EMD 121974) in patients with metastatic melanoma. Melanoma Res 22: 294-301, 2012. 
$18 \mathrm{Wu}$ YJ, Neuwelt AJ, Muldoon LL and Neuwelt EA: Acetaminophen enhances cisplatin- and paclitaxel-mediated cytotoxicity to SKOV3 human ovarian carcinoma. Anticancer Res 33: 2391-2400, 2013.

$19 \mathrm{Wu}$ YJ, Muldoon LL, Dickey DT, Lewin SJ, Varallyay CG and Neuwelt EA: Cyclophosphamide enhances human tumor growth in nude rat xenografted tumor models. Neoplasia 11: 187-195, 2009.

20 Muldoon LL, Gahramanov S, Li X, Marshall DJ, Kraemer DF and Neuwelt EA: Dynamic magnetic resonance imaging assessment of vascular targeting agent effects in rat intracerebral tumor models. Neuro Oncol 13: 51-60, 2011.

21 Friedel $\mathrm{P}$ and Alexander S: Cancer invasion and the microenvironment: Plasticity and reciprocity. Cell 147: 9921009, 2011.

22 Puhalla S, Elmquist W, Freyer D, Kleinberg L, Adkins C, Lockman P, McGregor J, Muldoon L, Nesbit G, Peereboom D, Smith Q, Walker S and Neuwelt E: Unsanctifying the sanctuary: challenges and opportunities with brain metastases. Neuro Oncol 17: 639-651, 2015.

23 Winkler F: The brain metastatic niche. J Mol Med (Berl) 93: 1213-1220, 2015.

24 Weidle UH, Birzele F, Kollmorgen G and Ruger R: Dissection of the Process of Brain Metastasis Reveals Targets and Mechanisms for Molecular-based Intervention. Cancer Genomics Proteomics 13: 245-258, 2016.

25 Palmieri D, Bronder JL, Herring JM, Yoneda T, Weil RJ, Stark AM, Kurek R, Vega-Valle E, Feigenbaum L, Halverson D, Vortmeyer AO, Steinberg SM, Aldape K and Steeg PS: Her-2 overexpression increases the metastatic outgrowth of breast cancer cells in the brain. Cancer Res 67: 4190-4198, 2007.

26 Vogetseder A, Thies S, Ingold B, Roth P, Weller M, Schraml P, Goodman SL and Moch H: alphav-Integrin isoform expression in primary human tumors and brain metastases. Int $\mathrm{J}$ Cancer 133: 2362-2371, 2013.

27 Hood JD and Cheresh DA: Role of integrins in cell invasion and migration. Nat Rev Cancer 2: 91-100, 2002.

28 Ramsay AG, Marshall JF and Hart IR: Integrin trafficking and its role in cancer metastasis. Cancer metastasis reviews 26: 567 578, 2007.

29 Hoshino A, Costa-Silva B, Shen TL, Rodrigues G, Hashimoto A, Tesic Mark M, Molina H, Kohsaka S, Di Giannatale A, Ceder S, Singh S, Williams C, Soplop N, Uryu K, Pharmer L, King T, Bojmar L, Davies AE, Ararso Y, Zhang T, Zhang H, Hernandez J, Weiss JM, Dumont-Cole VD, Kramer K, Wexler LH Narendran A, Schwartz GK, Healey JH, Sandstrom P, Labori KJ, Kure EH, Grandgenett PM, Hollingsworth MA, de Sousa M, Kaur S, Jain M, Mallya K, Batra SK, Jarnagin WR, Brady MS, Fodstad O, Muller V, Pantel K, Minn AJ, Bissell MJ, Garcia BA, Kang Y, Rajasekhar VK, Ghajar CM, Matei I, Peinado H, Bromberg $\mathrm{J}$ and Lyden $\mathrm{D}$ : Tumour exosome integrins determine organotropic metastasis. Nature 527: 329-335, 2015.

30 Chen Q, Boire A, Jin X, Valiente M, Er EE, Lopez-Soto A, Jacob LS, Patwa R, Shah H, Xu K, Cross JR and Massaqué J: Carcinoma-astrocyte gap junctions promote brain metastasis by cGAMP transfer. Nature 533: 493-498, 2016.

31 Quail DF and Joyce JA: The Microenvironmental Landscape of Brain Tumors. Cancer Cell 31: 326-341, 2017.

32 Stupack DG and Cheresh DA: A Bit-role for integrins in apoptosis. Nat Cell Biol 6: 388-389, 2004
33 Guo W and Giancotti FG: Integrin signalling during tumour progression. Nat Rev Mol Cell Biol 5: 816-826, 2004.

34 Mitra SK and Schlaepfer DD: Integrin-regulated FAK-Src signaling in normal and cancer cells. Curr Opin Cell Biol 18: 516-523, 2006.

35 Morozevich GE, Kozlova NI, Chubukina AN and Berman AE: Role of integrin alphavbeta3 in substrate-dependent apoptosis of human intestinal carcinoma cells. Biochemistry (Mosc) 68: 416423, 2003.

36 Uhm JH, Gladson CL and Rao JS: The role of integrins in the malignant phenotype of gliomas. Front Biosci 4: D188-199, 1999.

37 Rapisarda V, Borghesan M, Miguela V, Encheva V, Snijders AP, Lujambio A and O'Loghlen A: Integrin Beta 3 Regulates Cellular Senescence by Activating the TGF-beta Pathway. Cell Rep 18: 2480-2493, 2017.

38 Gvozdenovic A, Boro A, Meier D, Bode-Lesniewska B, Born W, Muff R and Fuchs B: Targeting alphavbeta3 and alphavbeta5 integrins inhibits pulmonary metastasis in an intratibial xenograft osteosarcoma mouse model. Oncotarget 7: 55141$55154,2016$.

39 Xiong S, Klausen C, Cheng JC and Leung PCK: TGFbeta1 induces endometrial cancer cell adhesion and migration by upregulating integrin alphavbeta3 via SMAD-independent MEKERK1/2 signaling. Cell Signal 34: 92-101, 2017.

40 van den Hoogen C, van der Horst G, Cheung H, Buijs JT, Pelger $\mathrm{RC}$ and van der Pluijm G: Integrin alphav expression is required for the acquisition of a metastatic stem/progenitor cell phenotype in human prostate cancer. The American journal of pathology 179: 2559-2568, 2011.

41 van der Horst G, van den Hoogen C, Buijs JT, Cheung H, Bloys H, Pelger RC, Lorenzon G, Heckmann B, Feyen J, Pujuguet P, Blanque R, Clément-Lacroix $P$ and van der Pluijm G: Targeting of alpha(v)-integrins in stem/progenitor cells and supportive microenvironment impairs bone metastasis in human prostate cancer. Neoplasia 13: 516-525, 2011.

42 Lal S, Kersch C, Beeson KA, Wu YJ, Muldoon LL and Neuwelt EA: Interactions between alphav-Integrin and HER2 and Their Role in the Invasive Phenotype of Breast Cancer Cells In Vitro and in Rat Brain. PLoS One 10: e0131842, 2015.

43 Townsend PA, Villanova I, Uhlmann E, Peyman A, Knolle J, Baron R, Teti A and Horton MA: An antisense oligonucleotide targeting the alphaV integrin gene inhibits adhesion and induces apoptosis in breast cancer cells. Eur J Cancer 36: 397409, 2000.

44 Liu H, Park J, Manning C, Goehlmann HW and Marshall DJ: Metastatic signature in lung cancer is associated with sensitivity to anti-integrin alpha( $(\mathrm{V})$ monoclonal antibody intetumumab. Genes Chromosomes Cancer 53: 349-357, 2014.

45 Weber MR, Zuka M, Lorger M, Tschan M, Torbett BE, Zijlstra A, Quigley JP, Staflin K, Eliceiri BP, Krueger JS, Marchese P, Ruggeri $\mathrm{ZM}$ and Felding $\mathrm{BH}$ : Activated tumor cell integrin alphavbeta3 cooperates with platelets to promote extravasation and metastasis from the blood stream. Thromb Res 140(Suppl 1): $\mathrm{S} 27-36,2016$

46 McCarroll JA, Gan PP, Erlich RB, Liu M, Dwarte T, Sagnella SS, Akerfeldt MC, Yang L, Parker AL, Chang MH, Shum MS, Byrne FL and Kavallaris M: TUBB3/betaIII-tubulin acts through the PTEN/AKT signaling axis to promote tumorigenesis and anoikis resistance in non-small cell lung cancer. Cancer Res 75: 415-425, 2015 
47 Kanojia D, Morshed RA, Zhang L, Miska JM, Qiao J, Kim JW, Pytel P, Balyasnikova IV, Lesniak MS and Ahmed AU: betaIIITubulin Regulates Breast Cancer Metastases to the Brain. Mol Cancer Ther 14: 1152-1161, 2015.

48 Jiang Y, Dai J, Yao Z, Shelley G and Keller ET: Abituzumab targeting of alphaV-class integrins inhibits prostate cancer progression. Mol Cancer Res, 2017. doi: 10.1158/15417786.MCR-16-0447. [Epub ahead of print]

49 Cai QQ, Dong YW, Wang R, Qi B, Guo JX, Pan J, Liu YY, Zhang CY and Wu XZ: MiR-124 inhibits the migration and invasion of human hepatocellular carcinoma cells by suppressing integrin alphaV expression. Sci Rep 7: 40733, 2017.

50 Montenegro CF, Casali BC, Lino RLB, Pachane BC, Santos PK, Horwitz AR, Selistre-de-Araujo HS and Lamers ML: Inhibition of alphavbeta3 integrin induces loss of cell directionality of oral squamous carcinoma cells (OSCC). PLoS One 12: e0176226, 2017.

51 De Franceschi N, Hamidi H, Alanko J, Sahgal P and Ivaska J: Integrin traffic - the update. J Cell Science 128: 839-852, 2015.
52 Arjonen A, Alanko J, Veltel S and Ivaska J: Distinct recycling of active and inactive $\beta 1$ integrins. Traffic 13: 610-625, 2012.

53 White DP, Caswell PT and Norman JC: $\alpha v \beta 3$ and $\alpha 5 \beta 1$ integrin recycling pathways dictate downstream Rho kinase signaling to regulate persistent cell migration. J Cell Biol 177: 515-525, 2007.

54 Reticker-Flynn NE, Malta DF, Winslow MM, Lamar JM, Xu MJ, Underhill GH, Hynes RO, Jacks TE and Bhatia SN: A combinatorial extracellular matrix platform identifies cellextracellular matrix interactions that correlate with metastasis. Nat Commun 3: 1122, 2012.
Received May 22, 2017

Revised June 1, 2017

Accepted June 14, 2017 